\title{
CONTINUUM GENERATION IN PHOTONIC CRYSTAL FIBRES BY MULTI-WAVELENGTH AMPLIFIED SUB-NANOSECOND LIGHT PULSES
}

\author{
A. Čiburys, R. Gadonas, and D. Jokšas \\ Department of Quantum Electronics, Vilnius University, Sauletekio 9, LT-10222 Vilnius, Lithuania \\ E-mail: arunas.ciburys@ ff.vu.lt
}

Received 16 October 2009; revised 18 March 2010; accepted 19 March 2010

\begin{abstract}
We report the results of experimental study of a white-light supercontinuum generation in single-mode air-silica microstructured fibres under sub-nanosecond single and dual wavelength pumping. We show that simultaneous excitation of the microstuctured fibre in its normal and anomalous dispersion regimes using the fundamental and second harmonic signals of a passively Q-switched microchip laser results in extension of the spectral range covered by homogeneous supercontinuum to the UV range up to $375 \mathrm{~nm}$.
\end{abstract}

Keywords: supercontinuum, photonic crystal fibre

PACS: $42.50 . \mathrm{Nn}, 42.65 .-\mathrm{k}$

\section{Introduction}

Broadband, spatially coherent supercontinuum generation is widely studied due to its applications in spectroscopy, optical metrology, microscopy, biomedical optics, etc. Recently, photonic crystal fibres $(\mathrm{PCFs})$ have been introduced as highly nonlinear media for continuum generation, enabling efficient conversion of sub-nanosecond IR pulses of Q-switched lasers into broadband radiation, covering visible and NIR spectral range. Single transversal mode character of supercontinuum supported by PCFs results in high spatial coherence of output radiation required in most applications. However, lack of brightness in blue-violet and particularly UV range is common disadvantageous feature of the continuum generated. Various methods have been employed for generation of continuum covering blueviolet and near UV range (below $400 \mathrm{~nm}$ ). Continuum generation at dual-wavelength pump was the first approach enabling extension of spectral range as demonstrated by Champert et al. [1]. Using this approach the wide spectrum radiation covering the wavelength range from 400 to $700 \mathrm{~nm}$ in photonic crystal fibre with $870 \mathrm{~nm}$ zero dispersion wavelength (ZDW) was generated. The main nonlinear process resulting in spectral broadening of the visible pump was found to be cascaded cross-phase modulation induced by the infrared part of the continuum [2]. Other methods for covering near UV range have been proposed [3-5] which rely on engineering of dispersion of the PCF fibre itself and using single wavelength radiation for excitation. One of the methods proposed is shifting the ZDW of the fibre to much shorter wavelengths by tapering PCF and using shorter pump wavelength [3,4] for excitation. Another approach is fabrication of photonic crystal fibres with a continuously decreasing ZDW along the fibre and using pumping at $1064 \mathrm{~nm}$ [5].

In this paper we report on results of continuum generation in two different photonic crystal fibres with different zero dispersion wavelengths and using pump radiation of two wavelengths - fundamental and second harmonics (SH) of passively Q-switched solid state Nd:LSB microlaser.

\section{Experimental set-up}

Sub-nanosecond pulses of Nd:LSB laser (wavelength $1062 \mathrm{~nm}$, pulse duration $500 \mathrm{ps}$, repetition rate $1 \mathrm{kHz}$, max. pulse energy $6 \mu \mathrm{J}$, Standa Ltd) were used as a pump. In order to ensure pulses' energies for continuum generation at different wavelengths, output pulses of Q-switched Nd:LSB laser have been amplified in ytterbium doped fibre amplifier pumped by $\mathrm{CW}$ laser diode. For amplification (Fig. 1) we used $2 \mathrm{~m}$ long double-cladding ytterbium doped fibre (cladding ab- 


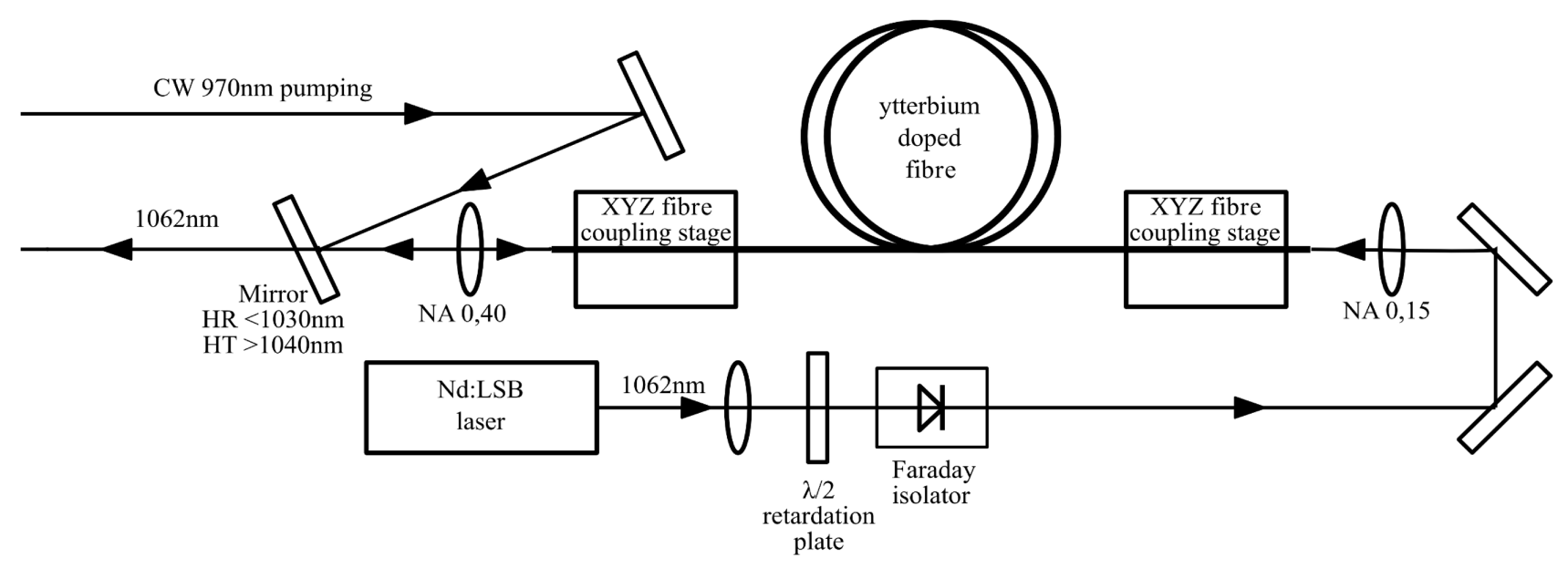

Fig. 1. Experimental set-up of ytterbium doped fibre amplifier.

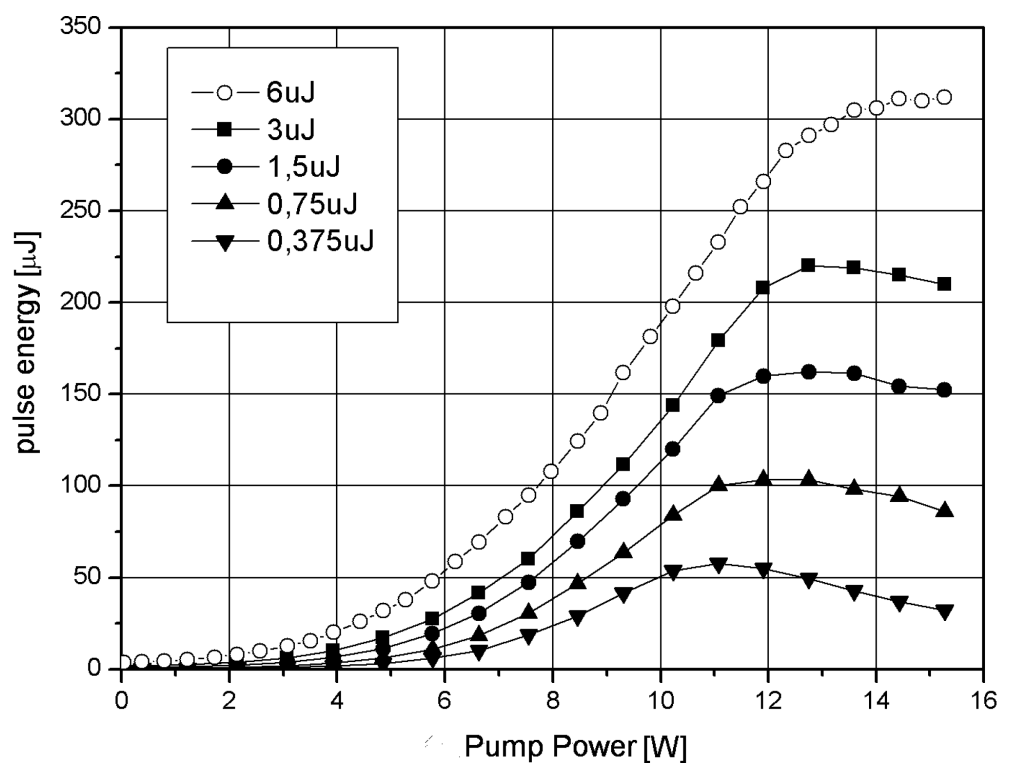

Fig. 2. Dependence of amplified pulse energy on CW laser diode pump power at different energy of seed pulses.

sorption of $\sim 5.5 \mathrm{~dB} / \mathrm{m}$ peaked at $975 \mathrm{~nm}$, core numerical aperture 0.07 , core diameter $25 \mu \mathrm{m}$, cladding diameter $250 \mu \mathrm{m}$, cladding numerical aperture 0.46, manufactured by Nufern Corp.). Ytterbium doped fibre was pumped at counter-direction by $\mathrm{CW}$ laser diode (970 nm, max. power $30 \mathrm{~W}$ ). The maximum amplified pulse energy achieved was $365 \mu \mathrm{J}$ (Fig. 2) which was limited by competitive amplification of spontaneous emission at $1030 \mathrm{~nm}$. The measured quality parameter $M^{2}$ of amplified beam was $\sim 1.3$.

The fundamental and second harmonics of amplified laser output radiation were used for pumping of PCFs. Amplified beam of fundamental radiation was divided into two equal power beams by beam splitter $V_{1}$. One of the beams was used for generation of second harmonic in nonlinear KTP crystal of $6 \mathrm{~mm}$ length. Half-wave

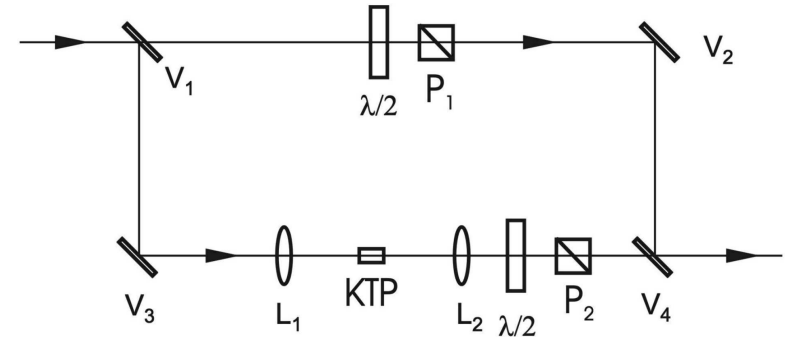

Fig. 3. Experimental set-up for dual-wavelength pump of PCF.

plates and polarizers $\left(P_{1}, P_{2}\right)$ were used for control of power in both fundamental and SH beams independently (Fig. 3). Then the beams of fundamental and $\mathrm{SH}$ were superimposed by dichroic mirror $V_{4}$ on entrance of coupling $20 \times$ microscope objective lens. The moving of collimating lens $L_{2}$ after KTP crystal was used to counterbalance the chromatic aberration of coupling 


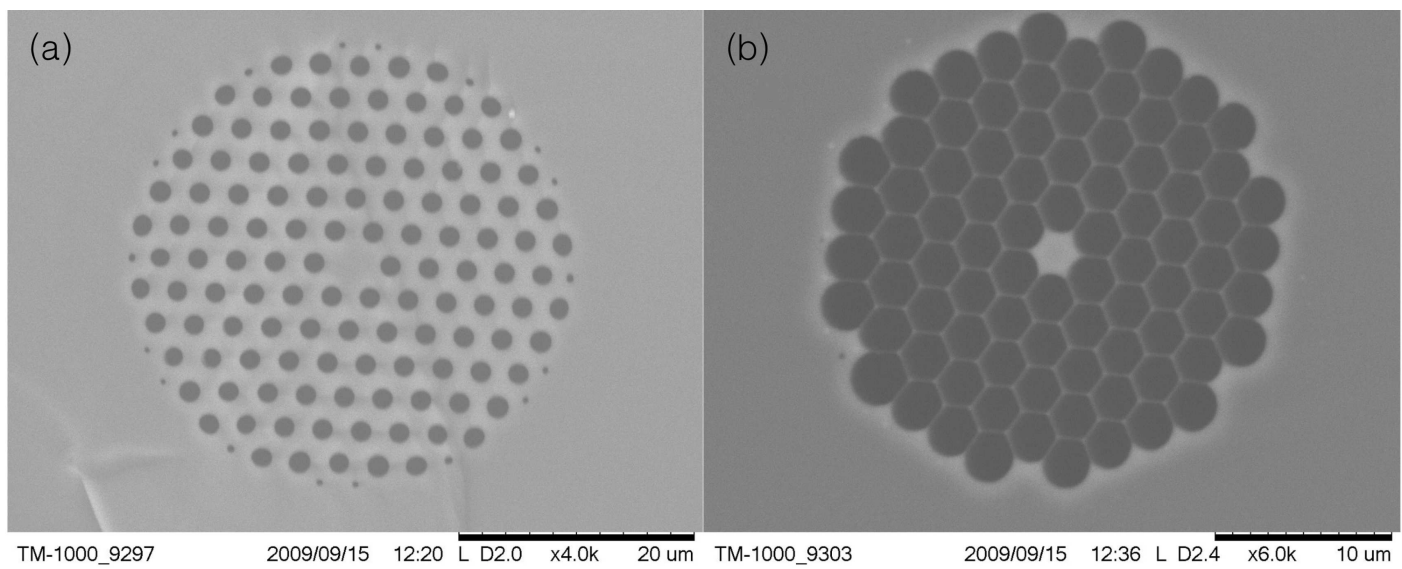

Fig. 4. Cross-section of photonic crystal fibres:(a) with ZDW at $1040 \mathrm{~nm}$, (b) with ZDW at $800 \mathrm{~nm}$.

objective lens. The power ratio of fundamental and second harmonic radiation at the input of PCF was kept at 5:1. The power of fundamental radiation was tuned from 9 to $25 \mathrm{~mW}$ (SH from 1.5 to $5 \mathrm{~mW}$ ). For generation of supercontinuum we used two different solid core PCFs with ZDW at 1040 and $800 \mathrm{~nm}$. The structure of the fibres is shown in Fig. 4. The fibre with lower air filling factor had ZDW at $1040 \mathrm{~nm}$, so the fundamental of the pump laser hit the anomalous dispersion region near ZDW. The fibre used had $20 \mathrm{~m}$ length (core diameter $4.8 \pm 0.2 \mu \mathrm{m}$, pitch (distance between cladding holes) $3.2 \pm 0.1 \mu \mathrm{m}$, air hole diameter $1.7 \pm 0.1 \mu \mathrm{m}$, diameter of holey region $37 \pm 0.5 \mu \mathrm{m})$. Another fibre with solid core and high air filling factor of holey region had ZDW at $800 \mathrm{~nm}$ (core diameter $2.4 \pm 0.2 \mu \mathrm{m}$, pitch $2.9 \pm 0.1 \mu \mathrm{m}$, air filling factor in the holey region $90 \%$, diameter of holey region $27 \pm 0.5 \mu \mathrm{m}$, fibre length $10 \mathrm{~m}$, manufactured by Crystal Fibre A/S). Spectra of generated continuum were measured by spectrometer AvaSpec 20482TEC(Avantes BV).

\section{Results and discussion}

Separate pumping by either fundamental or second harmonics as well as pumping by both beams was used in order to elucidate the influence of single and dual wavelength pumps on spectral characteristics of continuum generated in PCF. For PCF with ZDW at $1040 \mathrm{~nm}$ the measured output spectra are shown in Fig. 5. The pumping at $1062 \mathrm{~nm}$ is seen to produce a flat and homogeneous continuum in the visible range extending to the blue up to $475 \mathrm{~nm}$. Modulation instability is considered to be one of the main nonlinear processes for generation of broad supercontinuum in the anomalous dispersion regime especially in vicinity of zero dispersion wavelength. At initial stage of supercontinuum formation, the Stokes and anti-Stokes sidebands are generated due to modulation instability. At further propagation in PCF the phase-matched four wave mixing process starts to play crucial role in excitation of new spectral components and in the spectral broadening. The higher order nonlinear processes, such as stimulated Raman scattering or third order dispersion, affect the formation of supercontinuum too $[6,7]$. While only second harmonic was used for pumping, stimulated Raman scattering was found to be the dominating nonlinear process in this case due to the strong normal dispersion of the fibre at $532 \mathrm{~nm}$. In this case, few Raman Stokes sidebands could be observed but no parametric processes which broaden the spectrum on the blue side took place. In the case when dual wavelength pumping was realized, i.e. both fundamental and second harmonic were launched into PCF, a flat and homogeneous continuum as in the first case, but with few intense lines due to cascaded stimulated Raman scattering of second harmonic, was observed. No additional broadening of continuum to UV was observed due to adding the second harmonic pump. As in the case of pumping at $1062 \mathrm{~nm}$, the short wavelength part of the spectrum was limited at $475 \mathrm{~nm}$. Increase of pump power at $1062 \mathrm{~nm}$ resulted only in increase of the spectral brightness of the blue part of the visible spectrum (Fig. 6). The second PCF was chosen so that the zero dispersion wavelength of the fibre would be located between the two pump wavelengths. The longer pump wavelength is in region of anomalous dispersion, whereas the shorter (visible) falls in the region of normal dispersion. In this case no continuum generation in visible range at $1062 \mathrm{~nm}$ pump was observed. Although the spectral broadening of infrared part of the spectrum has not been examined due to limited spectral sensitivity of spectrometer, it has been shown in [2] 


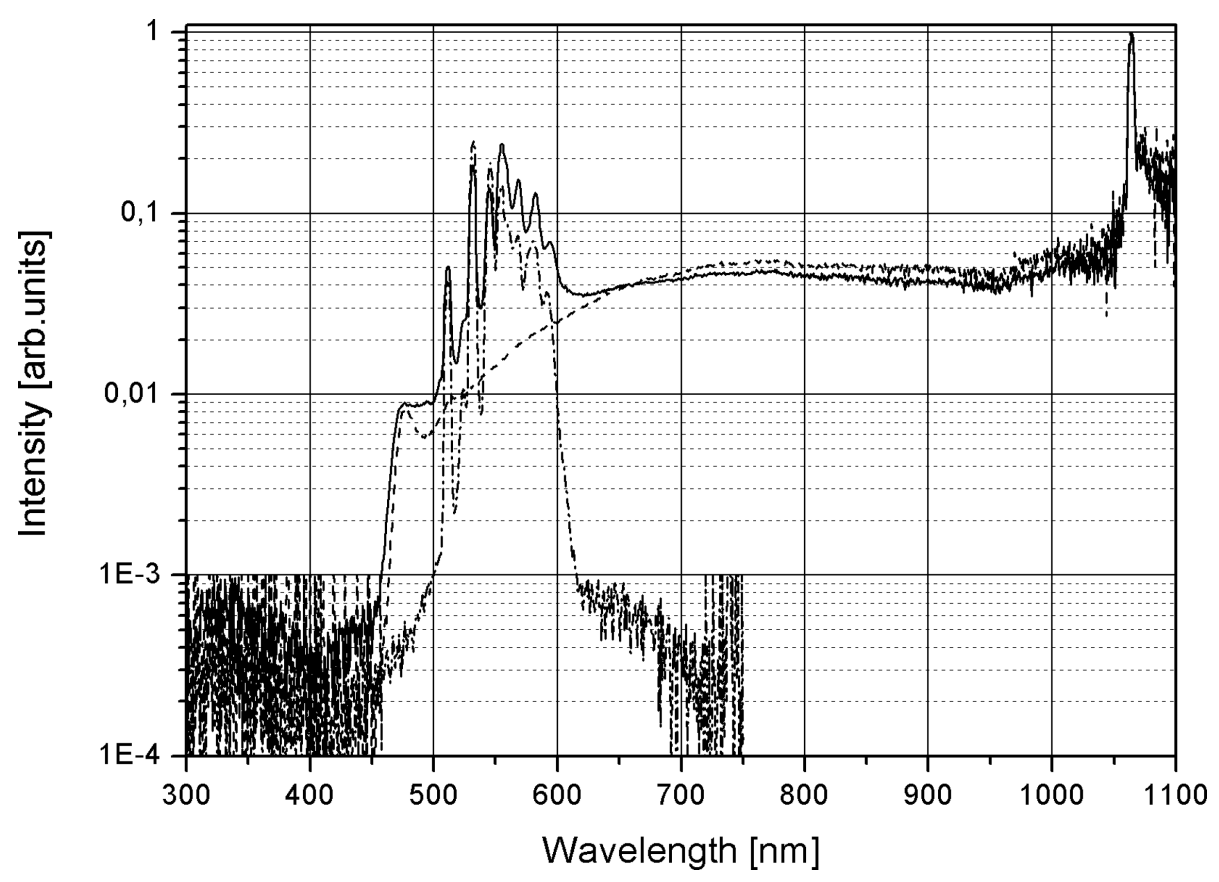

Fig. 5. Spectra of continuum generated in PCF with ZDW at $1040 \mathrm{~nm}$. (- - - -) pump at $1062 \mathrm{~nm}$ (pump power $20 \mathrm{~mW}$ ), (- - - ) pump at $531 \mathrm{~nm}$ (pump power $4 \mathrm{~mW}$ ), (_ ) dual-wavelength pump at $1062 \mathrm{~nm}$ (pump power $20 \mathrm{~mW}$ ) and $531 \mathrm{~nm}$ (pump power $4 \mathrm{~mW}$ ).

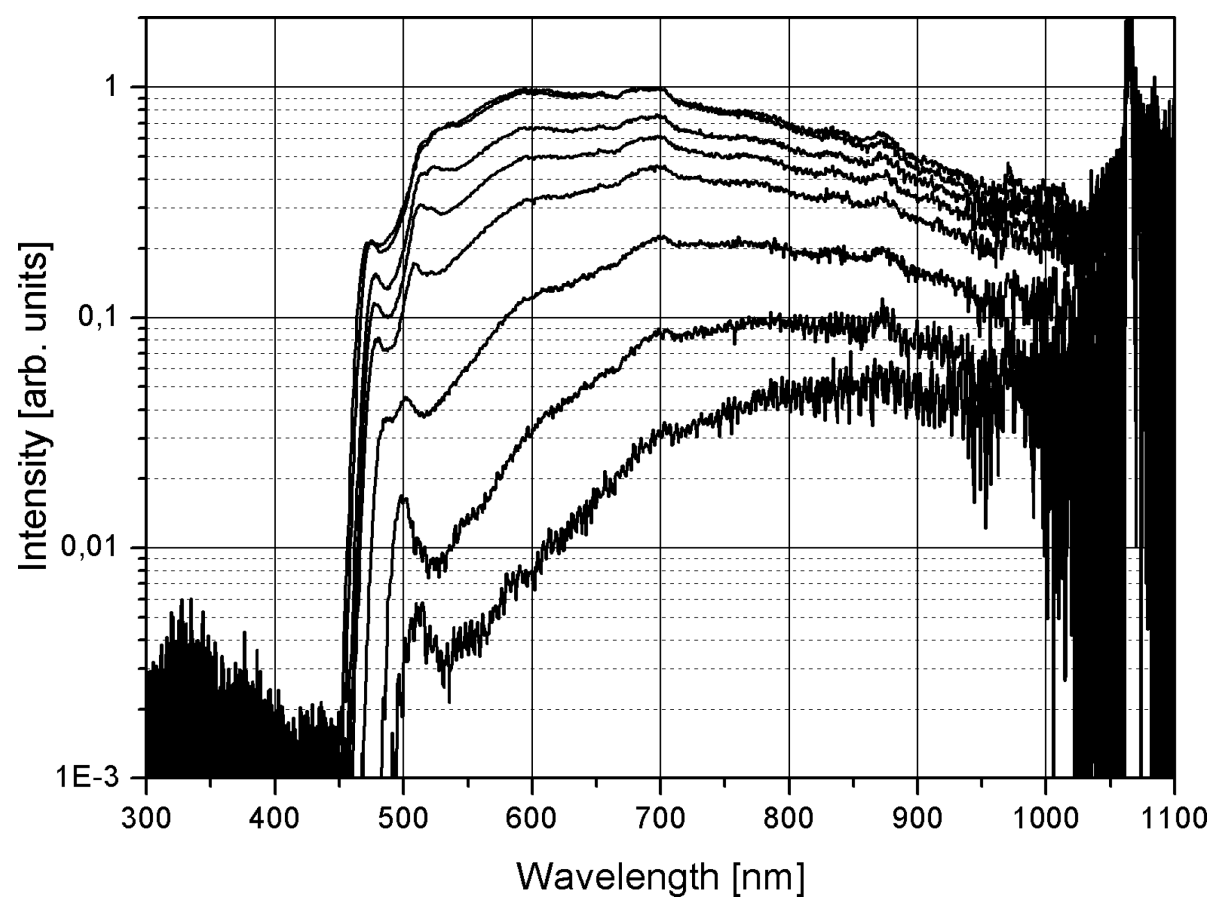

Fig. 6. Dependence of the spectrum of continuum generated in PCF with ZDW at $1040 \mathrm{~nm}$ on pump power at $1062 \mathrm{~nm}$ (from 9 to $25 \mathrm{~mW}$ ).

that at initial stage of beam propagation in fibre symmetrical sidebands are generated due to modulation instability. With further propagation, multiple sidebands grow from noise, but only the spreading of continuum to longer wavelength side occurs due to overlap with Raman bandwidth [2]. More than six Stokes shifted and broadened Raman lines were generated in the case of pumping of this PCF by second harmonic. However, at dual wavelength pumping the spectral coverage of the continuum generated was significantly enlarged at short wavelength side compared to second harmonic pump of the same fibre and the case of $1062 \mathrm{~nm}$ pump of PCF with ZDW at $1040 \mathrm{~nm}$ (Fig. 7). As in the case of dual wavelength pump of $1040 \mathrm{~nm}$ ZDW fibre, broadening of continuum saturates at specific wavelength, and further increasing of pump power does not influence the 


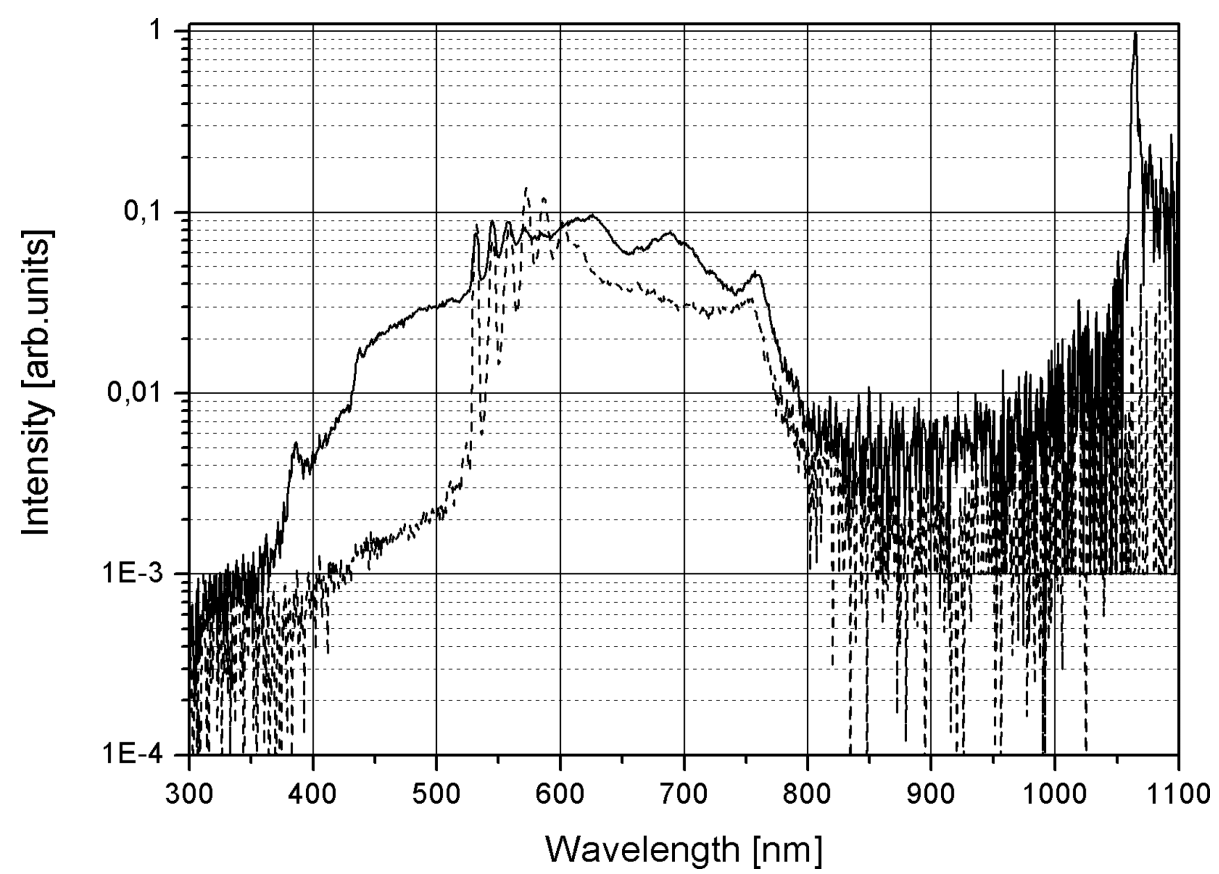

Fig. 7. Spectra of continuum generated in PCF with ZDW at $800 \mathrm{~nm}$. (- - - -) pump at $531 \mathrm{~nm}$ (pump power $4 \mathrm{~mW}$ ), ( $(-)$ dual-wavelength pump at $1062 \mathrm{~nm}$ (pump power $20 \mathrm{~mW}$ ) and $531 \mathrm{~nm}$ (pump power $4 \mathrm{~mW}$ ).

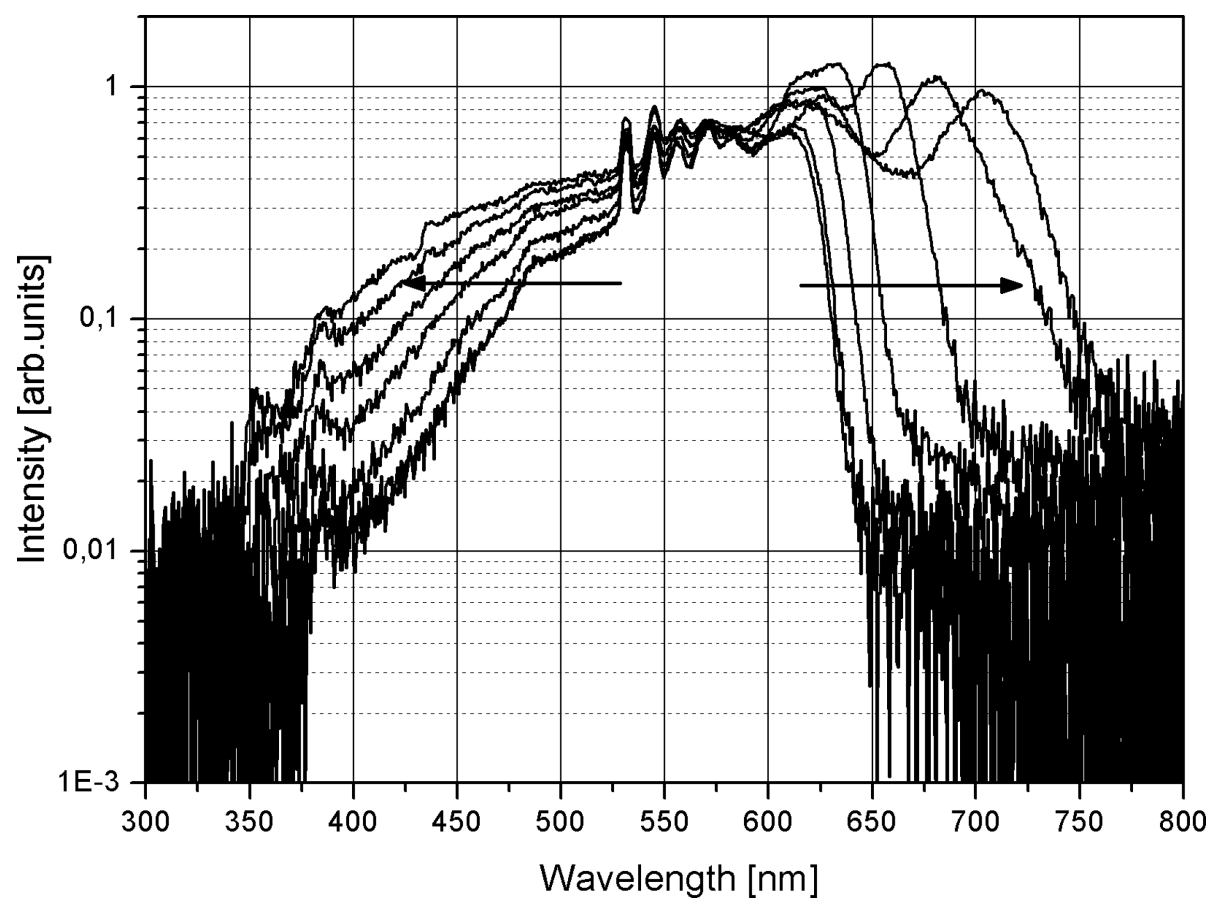

Fig. 8. Dependence of the spectrum of continuum generated at dual wavelength pump on pump power (from 9 to $25 \mathrm{~mW}$ and from 1.5 to $5 \mathrm{~mW}$ at $1062 \mathrm{~nm}$ and $531 \mathrm{~nm}$ respectively) for PCF with ZDW at $800 \mathrm{~nm}$. Arrows indicate broadening of continuum spectrum with increasing the pump power.

cutoff wavelength. Extension of the spectral coverage of the continuum to the blue up to $365 \mathrm{~nm}$ was achieved in this case, but no significant influence of dual pump on spectral shape of the continuum in NIR (between 800 and $1050 \mathrm{~nm}$ ) was observed (Fig. 8). Considerable broadening of the spectrum to UV could be ex- plained as a result of cross phase modulation of visible radiation by spectrally broadened infrared part of the continuum. Newly generated infrared spectral components influence the modulation instability around the visible pump wavelength by cascaded cross phase modulation. A broadening to blue evolves due to multiple 
cross phase modulation interactions [2]. The main process of broadening to the red in the visible part of the continuum remains stimulated Raman scattering.

\section{Conclusions}

Our experimental results demonstrate considerable extension of the spectral coverage of supercontinuum to the blue-UV range by dual wavelength pump of PCF both in normal and anomalous dispersion regions. Cross phase modulation between visible and IR parts of continuum enable one to cover the whole visible spectrum up to $365 \mathrm{~nm}$ in the PCF with $800 \mathrm{~nm}$ ZDW. Dual wavelength pump of PCF offers the way to create compact sources of spatially coherent light based on Q-switched microlasers.

\section{Acknowledgement}

This work is supported by the Lithuanian State Science and Studies Foundation, Grant B10/08 "BroadBand Microlasers for Spectroscopy and Diagnostics" (CONTILAS).

\section{References}

[1] P.-A. Champert, V. Couderc, Ph. Leproux, S. Février, V. Tombelaine, L .Labonté, Ph. Roy, and Cl. Froehly, Opt. Express 12(19), 4366 (2004).

[2] E. Raikkonen, G. Genty, O. Kimmelma, M. Kaivola, K.P. Hansen, and S.C. Buchter, Opt. Express 14(17), 7914 (2006).

[3] C. Xiong, A. Witkowska, S.G. Leon-Saval, T.A. Birks, and W.J. Wadsworth, Opt. Express 14(13), 6188 (2006).

[4] S.G. Leon-Saval, T.A. Birks, W.J. Wadsworth, P.St.J. Russell, and M.W. Mason, Opt. Express 12(13), 2864 (2004).

[5] A. Kudlinski, A.K. George, J.C. Knight, J.C. Travers, A.B. Rulkov. S.V. Popov, and J.R. Taylor, Opt. Express 14(12), 5715 (2006).

[6] W.J. Wadsworth, N. Joly, J.C. Knight, T.A. Birks, F. Biancalana, and P.St.J. Russell, Opt. Express 12(2), 299 (2004).

[7] A. Demircan and U. Bandelow, Opt. Commun. 244, 181 (2004).

\title{
KONTINUUMO GENERAVIMAS FOTONINIŲ KRISTALŲ ŠVIESOLAIDŽIUOSE KAUPINANT KELETO BANGOS ILGIŲ SUSTIPRINTAIS SUBNANOSEKUNDINIAIS ŠVIESOS IMPULSAIS
}

\author{
A. Čiburys, R. Gadonas, D. Jokšas \\ Vilniaus universitetas, Vilnius, Lietuva
}

\section{Santrauka}

Eksperimentiškai tirtas superkontinuumo generavimas vienmodžiuose fotoninių kristalų šviesolaidžiuose kaupinant vieno ir keleto bangos ilgių subnanosekundiniais šviesos impulsais. Kaupinant fo- toninių kristalų šviesolaidi anomaliosios ir normaliosios šviesolaidžio dispersijos srityse pasyviai moduliuotos kokybės mikrolazerio pagrindine ir antraja harmonikomis buvo pasiektas spektrinis superkontinuumo išplitimas į UV sriti iki $365 \mathrm{~nm}$. 